\title{
Development of Air Handling Unit for the Pharmaceutical Industry
}

\author{
Aviraj Madke \\ M-Tech Student, Department of Mechanical Engineering, Priyadarshini College of Engineering, Nagpur, \\ Maharashtra, 440019.E-mail: madkeaviraj@gmail.com
}

\begin{abstract}
An Air Handling Unit is a part of Heating, Ventilation, and Air Conditioning (HVAC) can be a critical system that affects the ability of a pharmaceutical facility to meet its objective of providing safe and effective product to the patient. Environmental control systems that are appropriately designed, built, commissioned, operated, and maintained can help ensure the quality of product manufactured in a facility, improve reliability, and reduce both initial costs and ongoing operating costs for a facility. The design of Air Handling Unit for the pharmaceutical industry requires additional considerations, particularly with regard to providing a clean and safe space environment. HVAC can consume a major portion of the energy used by a facility, and requires a blend of Good Engineering Practice (GEP) and Good Manufacturing Practice $(G M P)$.HVAC aims to make personnel comfortable and to protect both workers inside a facility and the environment outside a facility from airborne materials that could be hazardous. In pharmaceutical manufacturing facilities, there also is a specific requirement to control the impact of the environment on the finished product (to assure product quality).
\end{abstract}

Keywords- Blower, Cooling Coil, Hot water coil, Filtration System

\section{I- INTRODUCTION}

The design of Air Handling Unit for the pharmaceutical industry requires additional considerations, particularly with regard to providing a clean and safe space environment. HVAC can consume a major portion of the energy used by a facility, and requires a blend of Good Engineering Practice (GEP) and Good Manufacturing
Practice (GMP). HVAC aims to make personnel comfortable and to protect both workers inside a facility and the environment outside a facility from airborne materials that could be hazardous. In pharmaceutical manufacturing facilities, there also is a specific requirement to control the impact of the environment on the finished product (to assure product quality).

\section{II -METHOLOGY}

HVAC equipment helps to meet the user requirements for room environmental conditions. HVAC equipment serving GMP areas is intended to work in conjunction with associated controls and sequences of operation systems to:

- Relative Humidity

- Static Pressure - Static pressure is nothing but the excess pressure in the area with respect to atmosphere

- Differential Pressure - Differential pressure is nothing but the difference in static pressures between two adjacent areas

- Control airborne particles, dust and microorganisms.

This research will mainly be focusing on Design \&Development of HVAC System with respect to Pharmaceutical industry. We know that in Pharmaceutical industry it is set of rules, regulations, guidelines for construction of manufacturing facilities, manufacturing process and cleanliness. In this research 


\section{International Journal of Innovations in Engineering and Science, www.ijies.net}

we design components of the air handling unit are briefly described as below.

\section{Blower:}

This blower is direct driven using motor as a prime mover. Blower is provided in the unit. Main blower will supply air in the working area. The blower takes the air from the rooms as return air and delivers it to the controlled areas the specified conditioning.

\section{Cooling Coil:}

Chilled water produced by Chiller is circulated into the chilled water coils of air handling units for pre-cooling and dehumidification.

\section{Hot water coil:}

Hot water produced by heat pump is circulated into the hot water coils of air handling units for reheat.

\section{Filtration System:}

Fresh air is supplied through treated fresh air (TFA) unit through leak proof insulated duct which is connected to fresh air inlet of AHU. Further filtration of air carried out by Pre-Filter $10 \mu$ (G-4, 90-95\% down to $10 \mu)$, Fine Filter $3 \mu$ (F-7, 95\% down to $3 \mu)$, Intermediate Filter $0.3 \mu$ (F-9, 85\% down to $0.3 \mu)$ and HEPA Filter $0.3 \mu(\mathrm{H}-$ $14,99.999 \%$ down to $0.3 \mu$ ) are provided at supply air terminals.

\section{Air Distribution Network:}

An air distribution network is provided to supply the air delivered by the blowers into the working areas.

\section{Instrumentation and Control system:}

Temperature gauges and pressure gauges has been provided for measuring chilled water and hot water inlet and outlet temperature and pressure.

An HVAC System may include the following basic components or units.

- HVAC water chillers and heaters

- Hot water generator (if chiller does produce chilled water only) or furnace

- Chilled water pumps

- Cooling water pumps

- Electrical power supply control or Motor control center (MCC)

- Cooling towers

- Piping for chilled water and cooling water or condenser side water

- Valves for chilled water and cooling water sides

- Air handling units (AHUs), heating coils and cooling Coils

- Ducts in ventilation system (supply ducts and return ducts)

- Fan Coil Units (FCUs) and thermostats

- HVAC Diffusers and grills
- HVAC controls (instrumentation \& Control components) installed at various locations

- HVAC software for building HVAC control or building management system (BMS)

An Assembly of all above components forms an HVAC system

In the background of HVAC system, an HVAC water chiller produces chilled water which is then circulated throughout the building or space upto cooling coils in air handling units. Blowers move air on cooling coils which is then distributed into various portions of space or building for providing comfort or preserving goods/items as per HVAC design.

Air is distributed through supply ducts and return air is collected in air handling units with the help of return ducts. Chilled water and cooling water pumps provide energy to keep the chilled and cooling water moving.

HVAC Valves are also installed at various points in piping to ease the maintenance of HVAC system or for the sake of system control. Heating of air may be done with the help of HVAC heat pump, hot water generator or simply by furnace. Some industrial chillers also serve as heaters in winter season. Heating coils take the place of cooling coils in case of heating mode.

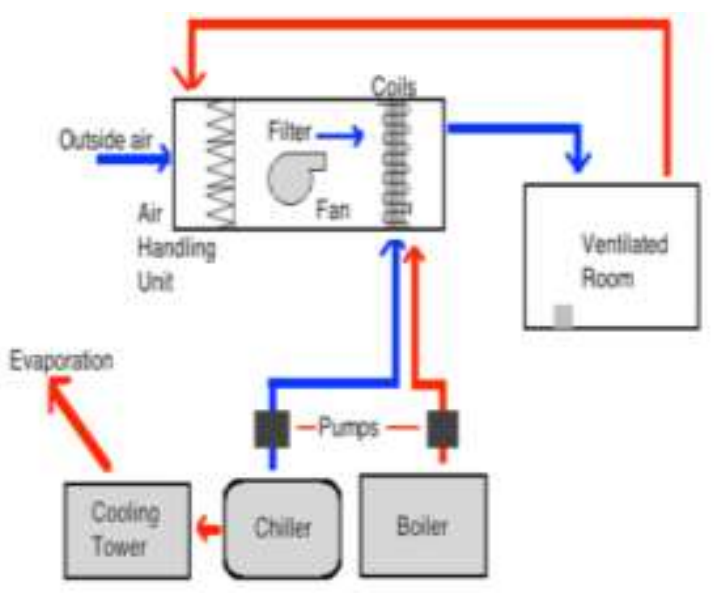

Fig.1- HVAC System

\section{III- CONCLUSION}

This research will mainly be focusing on Design \&Development of HVAC System with respect to Pharmaceutical industry. We know that in Pharmaceutical industry it is set of rules, regulations, guidelines for construction of manufacturing facilities, manufacturing process and cleanliness. 
https://doi.org/10.46335/IJIES.2021.6.11.6

e-ISSN: $2456-3463$

Vol. 6, No. 11, 2021, PP. 36-38

International Journal of Innovations in Engineering and Science, www.ijies.net REFERENCES

[1] Pharmaceutical engineering by C.V.S Subhramanyam, $3 r d$ edition, page no-407-429

[2] Ahmet Teke, Oguzhan Timur, Assessing the energy efficiency improve- ment potentials of HVAC systems considering economic and environmen-tal aspects at the hospitals, Renewable and Sustainable Energy Reviews, 33 pp. 224235, 2014..

[3] Wu Chen, Shiming Deng, Research on a novel DDCbased capacity con- troller for the directexpansion variable-air-volume A/C system, Energy Conversion and Management, 51 pp. 18, 2010.IoanDoroftei; Victor Grosu and VeaceslavSpinu; "Omnidirectional mobile robotDesign and Implimentation" from "Gh.Asachi" Technical university of lasi, Romania.

[4] Thiago Rodrigues Alves, Mario Buratto, Flavio Mauricio de Souza, Thelma Virginia Rodrigues, OpenPLC: An Open Source Alternative to Automation, IEEE Global Humanitarian Technology Conference, 978-1-4799-71930/14, 2014.Ilon, B. E. (1975). Wheels for a Course Stable Selfpropelling Vehicle Movable in any Desired Direction on the Ground or Some Other Base. U.S. Patent. U.S.A.

[5] Zafer Aydogmus, Omur Aydogmus, A Web-Based Remote Access Lab- oratory Using SCADA, IEEE Transactions on Education, Vol. 52, NO. 1, FEBRUARY 2009Diegel, O.; Badve, A.; Bright, G.; Potgieter, J. \&Tlatle, S. (2002). Improved Mecanum Wheel Design for Omni-directional Robots, Proc. 2002 Australian Conference on Robotics and Automation, Auckland, 27-29 Nov. 2002, pp. 117-121.

[6] Rockwell Automation Publication 1769-PP012CEN-E P.P.1-2 July 2013. [8] Rockwell Automation Publication 1756-RM094I-EN-P p.p.34 - Septem- ber 2015 